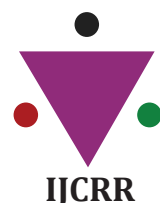

Section: Healthcare

ISI Impact Factor (2019-20): 1.628

IC Value (2019): 90.81 $\operatorname{SJIF}(2020)=7.893$

(c) (7) (3)

Copyright@IJCRR

\title{
Effect of Marriage on Women with Schizophrenia
}

\author{
Prakash B Behere ${ }^{1}$, Akshata N Mulmule², Debolina Chowdhury³, \\ Amit B Nagdive ${ }^{4}$, Aniruddh P Behere 5 , Richa Yadav6, Rouchelle Fernandes7
}

\begin{abstract}
'Former Vice Chancellor, D Y Patil University, Kolhapur (MS); Director Professor, Department of Psychiatry Jawahar Lal Nehru Medical College, Director School of Advanced Studies, Datta Meghe Institute of Medical Sciences (Deemed University), Sawangi, Wardha-442107, (Maharashtra), India; ${ }^{2}$ Psychiatry Registrar, Mental Health and ATODS Cairns Hospital, 165 Esplanade, Cairns City QLD 4870, Australia; ${ }^{2}$ Resident, Department of Psychiatry, ]awaharlal Nehru Medical College, Datta Meghe Institute of Medical Sciences (Deemed University), Wardha -442107, Maharashtra, India; ${ }^{4}$ Associate Professor, Department of Psychiatry, Jawaharlal Nehru Medical College, Datta Meghe Institute of Medical Sciences (Deemed University), Wardha -442107, Maharashtra, India; ${ }^{5}$ Helen Devos Children's Hospital, Assistant Professor, Department of Pediatrics and Human Development, Michigan State University College of Human Medicine Grand Rapids MI USA, Adjunct Faculty Datta Meghe Institute of Medical Sciences (Deemed University), Wardha-442107, India; ${ }^{6}$ Assistant Professor, Department of Psychiatry and Behavioural Sciences, OU College of Medicine, Oklahoma City, Oklahoma, USA Adjunct Faculty, Datta Meghe Institute of Medical Sciences (Deemed University), Wardha, India; 'Resident, Department of Psychiatry, Jawaharlal Nehru Medical College, Datta Meghe lnstitute of Medical Sciences (Deemed University), Wardha -442107, Maharashtra, India.
\end{abstract}

\section{ABSTRACT}

Background: Marriage is widely believed to be a cure for many types of mental disorders including psychoses, neurosis and hysteria, among the general populace. A common question posed by patients and their relatives to the treating psychiatrist, concerning the effects of marriage, either good or bad on patients suffering from schizophrenia. Keeping in view the enormity of this problem, studies of such are crucial in providing advice to both patients as well as their caregivers.

Objective: To study the effect of marriage on women with Schizophrenia in terms of demographic variables, marital characteristics and clinical outcome. Also to study and compare the severity of illness with family functioning and interaction in single and married women with Schizophrenia and to study marital adjustment in married women with schizophrenia.

Methods: The participants were assessed using a semi-structured pro forma to record demographic and socioeconomic variables, Brief Psychiatric Rating Scale, Family Assessment Device, Marital Adjustment Rating Scale, Family Interaction Pattern Scale and ICD-10 Criteria for diagnosis of Schizophrenia were administered.

Results: There was no significant difference between cases and controls in various sociodemographic variables except occupational background of both groups and a higher number of patients having longer (>10 years) duration of illness in the control group than cases. Chances of exacerbation of illness are more after marriage.

Conclusion: Marriage alone does not influence the severity of illness, family functioning and family interaction in both group and marital adjustment in married patients of schizophrenia.

Key Words: Family interaction, Female, Marriage, Schizophrenia

\section{INTRODUCTION}

Assessment of effects of marriage on persons of either gender with schizophrenia has generally been perplexing. Although a plethora of concepts and definitions have been associated with marriage, it is essentially a social process involving two individuals, who pledge to share life on a personal and intimate basis. The physical status and psyche of a person are primarily affected by marriage. Besides satisfying the biological need for sexual gratification in the most socially acceptable way, marriage also aids in achieving a sharp level of personality maturation. In Indian households, a large number of factors like caste regulation, geographical proximity, and astrological compatibility and dowry expectations play a vital role. Marriage is treated as an alliance between two families rather than a union between two individuals. A happy marriage may provide substantial emotionalbenefits. ${ }^{1}$ Gender differences (cultural scripts and biological susceptibility) are likely to complicate matters. Females with mental illness face multiple psycho-socio-economic problems as compared to males as males dominate over females in the Indian set-

\section{Corresponding Author:}

Prakash B Behere, Former Vice Chancellor, D Y Patil University, Kolhapur (MS); Director Professor, Department of Psychiatry Jawahar Lal Nehru Medical College, Director School of Advanced Studies, Datta Meghe Institute of Medical Sciences (Deemed University), Sawangi, Wardha-442107, (Maharashtra), India; Mobile: 9422840552; Email: pbbehere@gmail.com

ISSN: 2231-2196 (Print)

Received: 28.09 .2020
ISSN: 0975-5241 (Online)

Revised: 22.10 .2020
Accepted: 26.11 .2020

Published: 03.02 .2021 
ting. ${ }^{2}$ For a large number of Indian women, marriage is a once in a lifetime event linked mainly to social approval and glorification. Schizophrenia is a mental disorder characterized by disintegration of thought processes and emotional responsiveness along with other symptoms. It is a disorder that affects the way a person acts, thinks and have an altered perception of reality, often a significant loss of contact with reality. Marriage of a male and female schizophrenia patient is different as it is the female who leaves her family and enters a new one. Once married, the woman is expected to go to her husband's house and leave her parents house, where she is met with new responsibilities and new family members with different temperaments to deal with. If she is on maintenance drugs for psychoses, in-laws insist to find out the reason for medication, therefore she discontinues medications, which lead to relapse.

The parental, familial and social factors could often be a disadvantage to the psychiatric patient, more than is normal, leading to difficulties in marrying or sustaining a marriage.

In India, studies are scarce concerning this topic; as a result, many questions on this subject remain unanswered. ${ }^{3}$ The current study is a sincere attempt in this regard and at the closing stages of the study, we will know the influence of marriage on pre-existing mental disorders. Will be able to make out whether marriage is a boon or a bane, a curse or a blessing, to the women with schizophrenia.

\section{MATERIALS AND METHODS}

A total of 40 women participants with schizophrenia from the psychiatry OPD and IPDof a tertiary care unit of Medical College Hospital in central India were selected for study over one and half year period. Participants who got married after the illness started (the decision of marriage was of either family members or the patient herself), and who fulfilled the selection criteria were approached for participation in the study. They were explained about the nature of the study and after written informed consent/assent, various tools were applied. One key relative informant of every patient was also interviewed. Ethical Clearance was taken from the Institute Ethics Committee for Research on Human Subjects and confidentiality was ensured (DMIMS(DU) /IEC /958).

\section{Inclusion Criteria}

Participants who got married after the illness started (the decision of marriage was of either family members or the patient herself) as Cases and never married as Controls and who fulfilled the selection criteria (ICD-10 Criteria for Research)

\section{Exclusion Criteria}

1) Patients or Relatives who refused consent for the study
2) Patients without proper key informant

3) Patients having co-morbid physical or other psychiatric disorders

4) Patients or informants who were not able to communicate verbally.

\section{Procedures}

Semi-structured Proforma to record demographic, socio-economic and other variables:

Proforma was used to collect socio-demographic variables of patients (both married and never married).

\section{Brief Psychiatric Rating Scale (BPRS)}

The Brief Psychiatric Rating Scale (BPRS) to measure depression, anxiety, hallucinations and unusual behaviour. ${ }^{3}$ It has 24 Items on the scale. This scale has earlier been used in India. ${ }^{3,4}$

\section{Family Assessment Device (FAD)}

FAD is a 60-item self-report questionnaire with each item scored on a four-point scale (1-4), from 'strongly agree' to 'strongly disagree'.5

\section{Marital Adjustment Rating Scale (MARS)}

A 20 -item scale that measures marital satisfaction. It is a self-administered questionnaire given to the patient developed by Locke H. J., \& Wallace K. M. in $1959 .^{6}$ The Hindi version is used in the study. The Hindi version consists of 20 items which are answered on a variety of response scales. Score range from a minimum of 12 to a maximum of 110 . The more the score the better the adjustment perceived.

\section{Family Interaction Pattern Scale}

A Family Interaction Patterns Scale (FIPS) consisting of 6 items about the level of interaction among family members. It is a self-reported questionnaire developed by Bhatti in 1979.7

\section{Statistical analysis}

Statistical analysis was done by using descriptive and inferential statistics using Chi-square test, z-test, Pearson's Correlation Coefficient and Odd's Ratio. The data was collected and entries were done using SPSS version 17 software. Graph pad Prism 5.0 and $p<0.05$ is considered as the level of significance $(\mathrm{p}<00.05)$.

\section{RESULTS}

We interviewed 80 women with the diagnosis of schizophrenia, half of them were married (cases) and rest half (controls) were never married. Data were obtained from both in and outpatients. There was no significant difference between 
cases and controls in various sociodemographic variables except occupational background of both groups and the higher number of patients having longer ( $>10$ years) duration of illness in the control group than cases.

Sixty percentage of the cases in the study cohort were married and the decision of marriage in all the cases was made by their parents. Most of the patients got married within 5 years $(77.5 \%)$ of starting of illness. Only $32 \%$ of patients informed their spouses about their illness before marriage. The majority $(72 \%)$ of them had poor compliance for treatment after they got married and had exacerbation with increased frequency and severity ( $>2$ exacerbation in $35 \%$ females after marriage in contrast to $82.5 \%$ of $<2$ exacerbations before marriage).

Table 1 shows the comparison of the history of exacerbations of schizophrenia among cases and control group. It is observed that after comparing both the groups, chances of exacerbation of illness are more after marriage. The frequency of exacerbation is more in the married cohort ( $>2$ no of exacerbations in 55\% of married patients) and there is an increase in frequency if the patient is off medication in either cohort. Compliance for treatment is poorer in cases than single patients. However, none of either group tends to have good compliance for drugs in long term. ( $>5$ years duration).

Table 1: Comparison of exacerbation of illness and treatment history of Schizophrenia among cases \& controls

$\begin{array}{lcccc}\text { Exacerbation } & \begin{array}{c}\text { Case } \\ \text { Group } \\ (\mathbf{n}=\mathbf{4 0})\end{array} & \begin{array}{c}\text { Control } \\ \text { Group } \\ (\mathbf{n}=\mathbf{4 0})\end{array} & \text { N2-value } & \text { p-value } \\ \text { Yes } & 39(97.5 \%) & 31(77.5 \%) & & \\ \text { No } & 1(2.5 \%) & 9(22.5 \%) & 7.31 & \begin{array}{c}0.006 \\ \mathrm{p}<0.05\end{array}\end{array}$

No. of Exacerbation

$\begin{array}{lcccc}<2 & 2(5 \%) & 13(32.5 \%) & & \\ 2 & 16(40 \%) & 16(40 \%) & 11.73 & 0.002 \\ >2 & 22(55 \%) & 11(27.5 \%) & & \mathrm{p}<0.05\end{array}$

\section{Exacerbation on treatment}

$\begin{array}{llllc}<2 & 36(90 \%) & 34(85 \%) & & \\ 2 & 3(7.5 \%) & 6(15 \%) & 2.05 & 0.35 \\ >2 & 1(2.5 \%) & 0(0 \%) & & \end{array}$

Exacerbation off treatment

$\begin{array}{lcccc}<2 & 8(20 \%) & 18(45 \%) & & \\ 2 & 19(47.5 \%) & 14(35 \%) & 5.79 & 0.05 \\ >2 & 13(32.5 \%) & 8(20 \%) & & \mathrm{p}>0.05\end{array}$

Treatment Compliance

$\begin{array}{lllll}\text { Good } & 11(27.5 \%) & 21(52.5 \%) & 5.20 & \mathrm{p}<0.022 \\ \text { Poor } & 29(72.5 \%) & 19(47.5 \%) & & \mathrm{p}<0.05\end{array}$

Table 1: (Continued)

$\begin{array}{cccc}\text { Exacerbation } & \begin{array}{c}\text { Case } \\ \text { Group } \\ (\mathbf{n}=40)\end{array} & \begin{array}{c}\text { Control } \\ \text { Group } \\ (\mathbf{n}=40)\end{array} & \text { \$2-value }\end{array}$

\section{Duration of treatment}

\begin{tabular}{lcccc}
$<1$ yr & $12(30 \%)$ & $19(47.5 \%)$ & & \\
$1-5$ yrs & $19(47 \cdot 5 \%)$ & $12(30 \%)$ & & 0.24 \\
$6-10$ yrs & $5(12.5 \%)$ & $7(17.5 \%)$ & 4.16 & $\mathrm{p}>0.05$ \\
$>10$ yrs & $4(10 \%)$ & $2(5 \%)$ & & \\
\hline
\end{tabular}

Table 2 shows the opinion of relatives (informants who came with patients) and patients in both group on enquiring "Whether marriage can be considered as a cure for mental illness?" There was not much difference regarding opinion in relatives (mostly parents) in our study. With most of them considering marriage as a cure for mental illness (40-45\% of relatives in both groups consider marriage as a cure for mental illness Vs $32-35 \%$ does not consider it as a cure). On the contrary, lesser patients $(40 \%)$ in the control group in comparison to cases $(70 \%)$ were of opinion that marriage can be considered as a cure for mental illness. Thus it is a statistically significant difference in opinion.

Table 2: Opinion of relatives and patients regarding marriage and mental illness

\begin{tabular}{lcccc}
$\begin{array}{l}\text { Marriage and } \\
\text { mental illness }\end{array}$ & $\begin{array}{c}\text { Case Group } \\
(\mathbf{n}=40)\end{array}$ & $\begin{array}{c}\text { Control } \\
\text { Group } \\
(\mathbf{n}=40)\end{array}$ & N2-value & p-value \\
Relative's Opinion & & & \\
Cure & $16(40 \%)$ & $18(45 \%)$ & & 0.73 \\
Not cure & $13(32.5 \%)$ & $14(35 \%)$ & 0.62 & $\mathrm{p}>0.05$ \\
Not sure & $11(27.5 \%)$ & $8(20 \%)$ & & \\
Patient's opinion & & & & \\
Cure & $28(70 \%)$ & $16(40 \%)$ & & \\
Not cure & $4(10 \%)$ & $11(27.5 \%)$ & 7.73 & 0.021 \\
Not sure & $8(20 \%)$ & $13(32.5 \%)$ & & $\mathrm{p}<0.05$ \\
\hline
\end{tabular}

When we compared the association between exacerbations of illness in both groups concerning their educational background, the number of exacerbations in the case group remained similar. On the contrary in control group exacerbations decreased as the level of education increased (clearly evident in the education level of HSC wherein control group $>2$ frequency of exacerbation are lesser than $<2$ frequency in the same group and also $>2$ frequency in case group). This difference is statistically significant in comparison to the case group. $(<0.05)$

Mean score of Brief Psychiatry Rating Scale was 56.0 $(\mathrm{SD}=15.81)$ in married persons with schizophrenia and 58.12 $(\mathrm{SD}=16.95)$ in never-married persons with schizophrenia. 
There was no significant difference in the severity of mental illness among married and never married subjects. When we assessed the difference in mean and standard deviation in cases and controls according to family assessment device scale which is statistically non-significant. The results are comparable to each other with no difference in either group at all.

Table 3 depicts patients who are currently in marriage (20 married for the first time and 4 remarried. Total=24). It was observed that among the parameters assessed following had a negative correlation with the marital adjustments such as BPRS, FIPS, Impulsive self-harming attempt, family history of mental illness and the total duration of the marriage. Out of these BPRS, FIPS had statistically significant score suggesting that as the severity of illness increases or familial interaction becomes poor, marital adjustment deteriorates. It was seen that as the duration of marriage increases their adjustment becomes poorer. The marital adjustment seems to improve if there were children in the family.

Table 3: Marital adjustment rating scale in case group among married and remarried patients

\begin{tabular}{lccccc} 
Group & N & Mean & Std. Deviation & z-value & p-value \\
Married & 20 & 63.60 & \pm 17.06 & 3.87 & 0.001 \\
\hline
\end{tabular}

Table 4 deals with the comparison of score between three scales in the case group, the married females. It shows that as the severity of illness increases family functioning deteriorates, as there is a negative correlation. On the contrary on increase in illness severity, scores on FIPS increases thus depicting Antagonistic type of family interaction (poor interaction). The score of BPRS with FIPS is statistically significant.

Table 4: Correlation of severity of illness (by Brief Psychiatric Rating Scale scores) with family functioning (by Family Assessment Device and Family Interaction Pattern Scale) in Case Group

\begin{tabular}{lccccc} 
Scales & Mean & Std. Deviation & $\mathrm{N}$ & $\begin{array}{c}\text { Correlation } \\
\text { ' } \mathrm{r} \text { ' }\end{array}$ & $\mathrm{p}$-value \\
BPRS & 56.00 & 15.81 & 40 & - & - \\
FAD & 133.05 & 10.28 & 40 & -0.034 & 0.836 \\
FIPS & 11.80 & \pm 2.27 & 40 & 0.429 & 0.006 \\
\hline
\end{tabular}

Table 5 depicts that having children seemed to be a protective factor as $50 \%$ cases who were having children did not separate. The odds of separation were two times more in those who did not have children, the findings were statistically significant.
Table 5: Association of history of childbirth in married patients with a history of poor outcome of marriage (separation plus divorce after marriage)

\begin{tabular}{lccccc} 
Child & \multicolumn{3}{c}{ Poor Outcome } & Odd's & p-value \\
Birth & Yes & No & Total & Ratio & \\
Yes & $8(20 \%)$ & $20(50 \%)$ & $28(70 \%)$ & & \\
No & $8(20 \%)$ & $4(10 \%)$ & $12(30 \%)$ & 0.20 & 0.02 \\
Total & $16(40 \%)$ & $24(60 \%)$ & $40(100 \%)$ & & \\
\hline
\end{tabular}

Figure 1 and 2 shows that on the gross score it is seen that the patients in the control group had better interaction with their family members than cases (married patients). $42.5 \%$ of single patients had cordial relations with their family members in comparison to $17.5 \%$ of subjects in the case group.

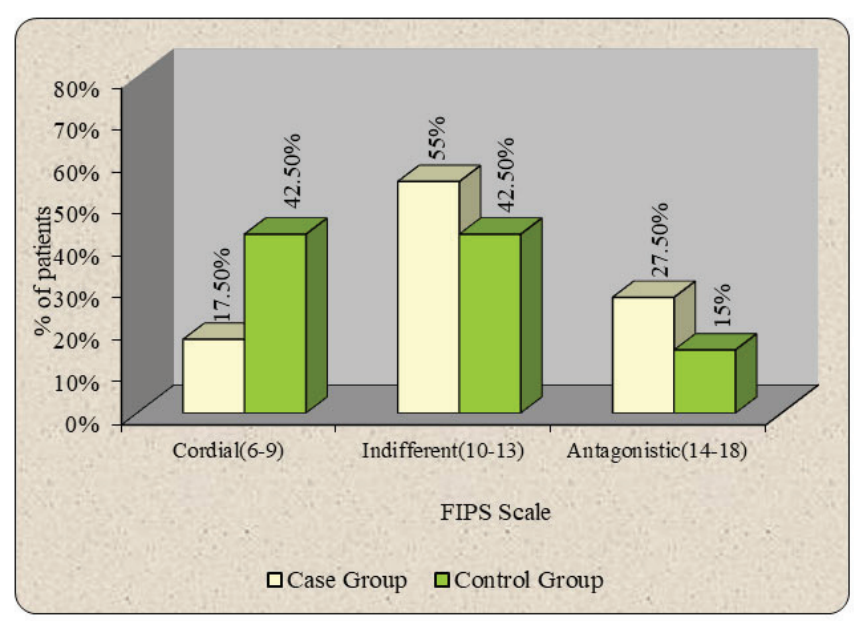

Figure 1: Comparison of Family Interaction Pattern Scale in case and control group.

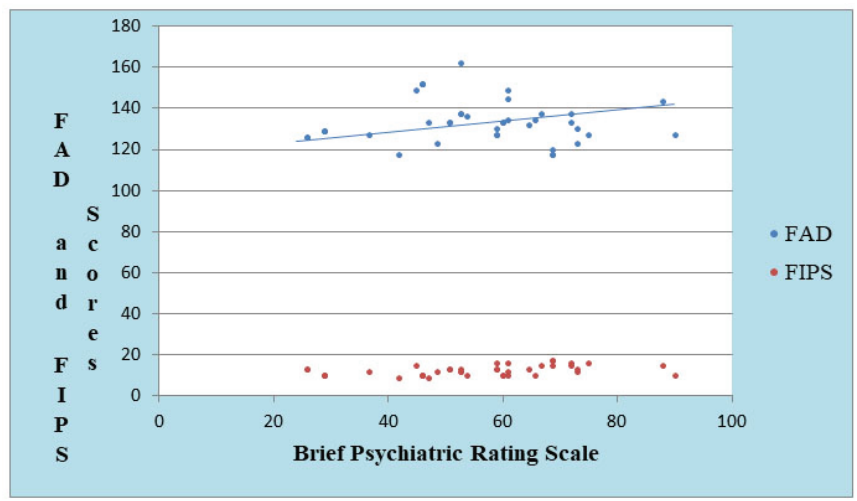

Figure 2: Shows correlation between severity of illness (BPRS) with family functioning (FAD and FIPS) in married patient. 


\section{DISCUSSION}

Marriages being a social process need certain skills to be successful. Marriage rates were much higher for Indians at the onset of psychosis. Ina study group, a strong gender difference was observed, women in India have a higher probability of getting married as compared to Indian men. ${ }^{8}$ Marriage and mental illness have always been a complicated matter. Marriage is widely believed to be a cure for many types of mental disorders as it grants a support system that helps individuals rise above certain life stressors. ${ }^{9}$

Considering the enormity of the problem this study was done out to provide some insight into the questions of the patient and family members. It was observed in the study that insidious onset and longer duration of illness did not reduce the chances of marriage. Most importantly, the age of onset of illness seemed to not affect the rate of marriage in both sexes. Those patients with early onset of illness may recover early enough to get married within 10 years of onset and lead a stable life..$^{10,11}$

It was seen in a cross-cultural study that initially married Indian women were almost seven times more likely to be married at follow-up than their initially never-married counterparts, even in comparison to women elsewhere. ${ }^{12}$ This is consistent to our findings that there were $60 \%$ of married women in cases group who were staying with their husband at the time of interview and out of which nearly $10 \%$ got remarried and had a good marital adjustment.

This has been consistent finding from several studies that individuals resort to hiding their mental illness due to fear of rejection from society or own people. ${ }^{13}$ We got some kind of results in our study where schizophrenic female patients in nearly $68 \%$ of cases did not reveal their illness to husbands before marriage. We found that the number of exacerbation decreased as patient maintained compliance for treatment. But since compliance was poor in case of the group the chances of exacerbation in them was significantly higher. However, very few patients in both the group were reluctant to continue treatment for a longer duration (up to 10 years or more).

Our study findings which showed that on an opinion poll that nearly $40 \%$ to $45 \%$ of patient's relatives in both groups thought that marriage is a cure for mental illness. But on the contrary $60 \%$ of patients in the control group were not in favour of this opinion that marriage can be considered a cure for mental illness. There was a significant difference in opinion of married patients and single ones where married patients were favouring marriage as a remedy for mental illness. Not in lines to the findings of our study, There was high morbidity from psychoses in the single and the divorced as compared with the married and the widowed, based on statistical and clinical material ${ }^{14}$ which was contrary to our study findings.
Similar to the findings in one of the previous study done on both male and female schizophrenic patients ${ }^{9}$ our study showed no significant effect of marriage over the severity as well as family functioning in both married and single patients. But it was seen that as the severity of mental illness increases the family functioning of patient decreases in both groups along with poor family interaction in married patients to a significant level. In our study, we found that having a child is a protective factor for separation from marriage. It was seen that nearly $50 \%$ of patients with schizophrenia who had children and did not separate. Consistent with our findings Thara et al in their study, also found that more women had broken marriages especially if they were childless. ${ }^{10,11}$

There are certain factors which act in favour of good marital adjustment in schizophrenics which are having the higher educational background, good familial support, lesser severity of illness, regular compliance for treatment and presence of the child in family. ${ }^{15,16}$ However, marriage per se alone does not influence the severity of illness, family functioning and family interaction in both group and marital adjustment in married patients of schizophrenia. ${ }^{16}$

In our study, we have the following limitations, as being trainees we have to complete our study in a stipulated period. Thus the study had small sample size. We could not do follow up and long term assessment as it was time-bound study. Recall bias while answering the questionnaire might be there. Some interviews were conducted when patients were under partial remission. This might have influenced some of the scores. It was a retrospective study. A prospective study would have been much better.

\section{CONCLUSION}

Marriage does act as a stepping stone in the life of an Indian female whether suffering from schizophrenia or not. There is the various situation which a woman has to deal with once she is married whether it may her education, occupation, type of family in which she is residing. The prognostic factors associated with her illness such as the family history of mental illness, duration of illness before marriage, type of schizophrenia, her compliance for treatment also has a major impact on further coarse of illness. There are certain myths related mostly concerning mental illness that it is a sort of distress relieved by marriage further adds to the misery in the way that guardian tends to marry their patients early once they are diagnosed to have a mental illness. In the process, they hide information from another party, stops medication resulting in exacerbation of illness. In certain situations, they even don't take the opinion of the patient regarding her marriage.

\section{Acknowledgement: None}


Declaration: Scientific Responsibility Statement The authors declare that they are responsible for the article's scientific content including study design, data collection, analysis and interpretation, writing, some of the mainline, or all of the preparation and scientific review of the contents and approval of the final version of the article.

Animal and human rights statement: All procedures performed in this study were following the ethical standards of the institutional and/or national research committee and with the 1964 Helsinki declaration and its later amendments or comparable ethical standards. No animal or human studies were carried out by the authors for this article.

Financial support and sponsorship: This research was partly supported by the Indian Council of Medical Research, New Delhi under MD thesis grant.

Conflict of interest: None of the authors received any other type of financial support that could be considered a potential conflict of interest regarding the manuscript or its submission.

Informed consent: Informed consent was obtained from all individual participants included in the study. Additional informed consent was obtained from the Key Relatives of patients.

\section{Ethical approval for study protocol /study design /Meth- odology:}

The study was approved by the Medical Ethics Committee of the Institute. Wardha, Maharashtra, India.

Contribution: This work was carried out in collaboration among all authors. All authors read and approved the final manuscript.

\section{REFERENCES}

1. Goel N, Behere P. Effect of marriage on clinical outcome of persons with the bipolar affective disorder: A case-control study. Int J Sci Study 2016;4:46-50.
2. Behere PB. Effect of marriage on pre-existing psychoses. Indian J Soc Psych 2019;35:10-12.

3. Inch R, Crossley M, Keegan D, Thorarinson D. Use of the Brief Psychiatric Rating Scale to measure success in a psychosocial day program. Psych Serv 1997;48(9):1195-1197.

4. Overall JE. The Brief Psychiatric Rating Scale. Psychol Rep 1962;10:799-812.

5. Locke HJ, Wallace KM. Short marital adjustment and prediction tests: Their reliability and validity. Marriage Fam Living 1959 Aug 1;21(3):251-255.

6. Epstein NB, Baldwin LM and Bishop DS. The McMaster Family Assessment Device. J Marital Fam Ther 1983. 9:171-180.

7. Bhatti RS. Social Diagnosis of Neurosis. Doctoral Thesis; Submitted to Bangalore University, Karnataka. 1979.

8. Hopper K, Wanderling J \& Narayanan P. To have and to hold: A cross-cultural inquiry into marital prospects after psychosis, Global Public Health: Int J Res Policy Pract 2007;2(3):257-280.

9. Behere PB, Sathyanarayana Rao TS, Verma K. Effect of marriage on pre-existing psychoses. Ind J Psychiatry 2011;53:287288.

10. Thara R, Srinivasan TN. Marriage And Gender in Schizophrenia. Indian J Psych 1997;39(1):64-69.

11. Thara R, Srinivasan TN. The outcome of marriage in schizophrenia. Soc Psych Psychiatr Epidemiol 1997;32:416-420

12. Behere PB, Verma K, Nagdive AB, Mansharamani H, Behere AP, Yadav R, et al. Is Marriage Solution for Persons with Schizophrenia? Med Sci 2020;24(104):2663-2674.

13. Akshata NM, Behere PB. Effect of marriage on women with schizophrenia: a preliminary study. J Datta Meghe Inst Med Sci Uni 2016;11(1):24-28.

14. Ornulv Odegard. New data on marriage and mental disease: the incidence of psychoses in the widowed and the divorced. Br J Psychiat 1953;99(417):778-785.

15. Behere PB. Effect of marriage on pre-existing psychoses. Ind J Soc Psychiat 2019;35:10-12.

16. Hailemariam M, Ghebrehiwet S, Baul T, Restivo JL, Shibre T, Henderson DC, et al. He can send her to her parents: The interaction between marriageability, gender and serious mental illness in rural Ethiopia. BMC Psychiat 2019;19(1):315. 